\title{
Method for improving photodynamic diagnosis and surgery of bladder tumours using cystoscopes
}

\author{
Lindvold, Lars René; Hermann, Gregers G.
}

\section{Published in:}

Proceedings of SPIE

Link to article, DOI:

$10.1117 / 12.2078780$

Publication date:

2015

Document Version

Publisher's PDF, also known as Version of record

Link back to DTU Orbit

Citation (APA):

Lindvold, L. R., \& Hermann, G. G. (2015). Method for improving photodynamic diagnosis and surgery of bladder tumours using cystoscopes. In Proceedings of SPIE (Vol. 9303). [93030V] SPIE - International Society for Optical Engineering. Proceedings of SPIE - The International Society for Optical Engineering https://doi.org/10.1117/12.2078780

\section{General rights}

Copyright and moral rights for the publications made accessible in the public portal are retained by the authors and/or other copyright owners and it is a condition of accessing publications that users recognise and abide by the legal requirements associated with these rights.

- Users may download and print one copy of any publication from the public portal for the purpose of private study or research.

- You may not further distribute the material or use it for any profit-making activity or commercial gain

- You may freely distribute the URL identifying the publication in the public portal 


\title{
Method for improving photodynamic diagnosis and surgery of bladder tumours using cystoscopes
}

\author{
Lars R. Lindvold*a and Gregers G. Hermann ${ }^{\mathrm{b}}$ \\ ${ }^{a}$ DTU Centre for Nuclear Technologies (NUTECH), Technical University of Denmark, Risø \\ Campus, DK 4000 Roskilde, Denmark; ${ }^{b}$ Urological Research Unit, Urology Departmenent, \\ Frederiksberg Hospital, DK 2000 Frederiksberg, Denmark
}

\begin{abstract}
We present a new concept on how to remove unwanted green fluorescence from urine during Photodynamic Diagnostics of tumours in the bladder using cystoscopy. A high power LED based light source $(525 \mathrm{~nm})$ has been made in our laboratory. This light source is tailored to match most commercially available rigid cystoscopes. A suitable spectral filter and adapter, for the eyepiece of the cystoscope, has been selected which allows the urologist to observe both red fluorescence from tumours and autofluorescence from healthy tissue at the same time.
\end{abstract}

Keywords: Cancer, urology, cystoscopy, photodynamic diagnosis, fluorescence imaging, high power LED

\section{INTRODUCTION}

Bladder cancer is the fourth most common cancer in men and the fifth most common cancer overall in northern Europe ${ }^{1}$. Due to long term survival and lifelong surveillance because of frequent tumour recurrences, bladder cancer has the highest cost per patient of all cancers from diagnosis to death ${ }^{2}$. Treatment of bladder tumours and surveillance of bladder cancer patients is performed by introducing a cystoscope through the urethra to the bladder. The bladder is illuminated in white light (Fig. 1).

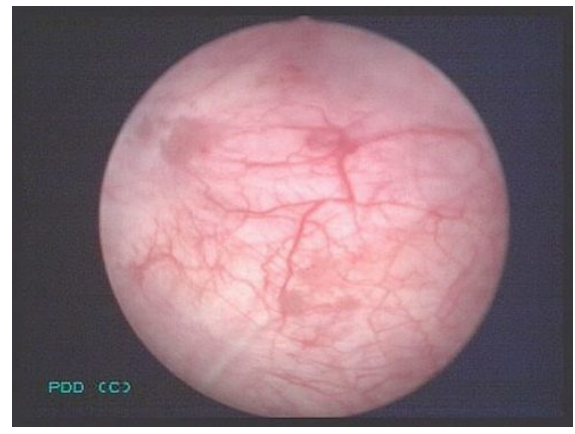

(a)

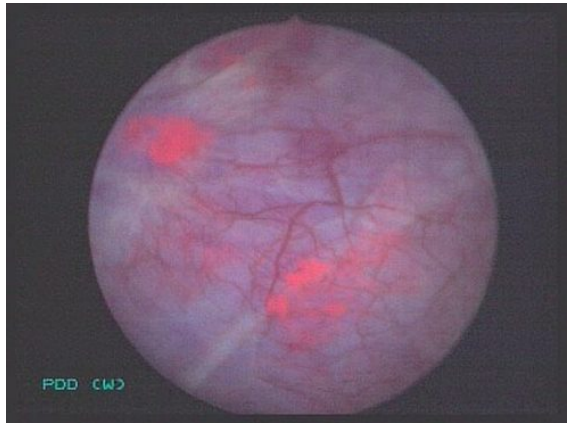

(b)

Figure 1. (a) The bladder of a patient observed in cystoscope under white light illumination. (b)The bladder of a patient observed through a $1.2 \mathrm{~cm}$ thick rigid steel cystoscope in the OR under blue light (430 $\mathrm{nm}$ ) illumination (PDD) showing red fluorescence from bladder tumour tissue (C) Gregers Hermann.

If a tumour is identified it is resected using an electrical sling introduced to the bladder through a $1.2 \mathrm{~cm}$ thick rigid steel cystoscope. This procedure requires general anaesthesia in an operating room (OR). Clinical studies have shown that in up to $49 \%$ of the procedures tumour tissue is left in the bladder after tumour resection in white light because of incomplete tumour resection and missed small tumours.

*lali@dtu.dk; phone +45 4677 4969; fax +45 4677 4959, www.nutech.dtu.dk

Photonic Therapeutics and Diagnostics XI, edited by Bernard Choi, et al., Proc. of SPIE Vol. 9303, 93030V · (C) 2015 SPIE - CCC code: 1605-7422/15/\$18 - doi: 10.1117/12.2078780 
The procedure becomes more complete when the resection is guided by photodynamic diagnosis (PDD) in blue light as more small tumours and remnant tumour tissue in the edge of the resection area are identified and subsequently removed. PDD relies on the fact that the uptake of a fluorescent dye, known as a photosensitiser ${ }^{3}$, is significantly larger in tumour tissue than healthy tissue. One hour before endoscopic examination of the bladder (cystoscopy), a $50 \mathrm{ml}$ solution of a photosensitiser precursor, the hexyl derivative of 5 -aminolevulininc acid (Hexvix ${ }^{\circledR}$, Photocure ASA, Oslo, Norway), is administered to the bladder through a catheter via the urethra. This substance is metabolised in the mitochondria of the tumour cells to the potent photosensitizer Protoporphyrin IX (PpIX) as a part of the heme cycle. PpIX emit red fluorescence $(635 \mathrm{~nm})$ making the tumours of the bladder fluoresce red when the bladder is illuminated by blue light $(430 \mathrm{~nm})$ through the cystoscope.

The use of blue light PDD during resection of bladder tumours reduces relapse of bladder tumours with 36\% during 12 months surveillance after tumour resection ${ }^{4}$ and cause a reduction of the health economic cost of bladder cancer ${ }^{5}$. The method is recommended in the European guidelines ${ }^{6}$ of bladder cancer treatment.

Surveillance of bladder tumour patients is traditionally performed in the outpatient department (OPD) using local anaesthesia, - thin flexible cystoscopes and white light. The diagnostic sensitivity of bladder cancer during surveillance by flexible cystoscopes would be improved by using blue light PDD as in the OR. A PDD video cystoscope was developed in collaboration with Karl Storz GmbH \& Co KG (PDD 11272 VPI, D-Light C Light source, Karl Storz, Tuttlingen, Germany). However, urine contains fluorescent metabolites ${ }^{7}$, typically riboflavines, which are excited to emit green fluorescence by the blue light used in PDD. The green fluorescence from these metabolites makes it very difficult for the urologist to see details in the bladder (Fig. 2). This impairs the use of PDD with flexible cystoscopes in the OPD. The green colour problem is limited in the OR because green fluorescent metabolites from the urine are diluted by continuous bladder irrigation and because of a higher intensity of blue light in the instruments used in the OR. Bladder irrigation is possible in the thick rigid cystoscopes used in the OR setting, but limited in the small flexible endoscopes used in the OPD. The use of PDD in the OPD is therefore of limited benefit, which the here presented method remedies.

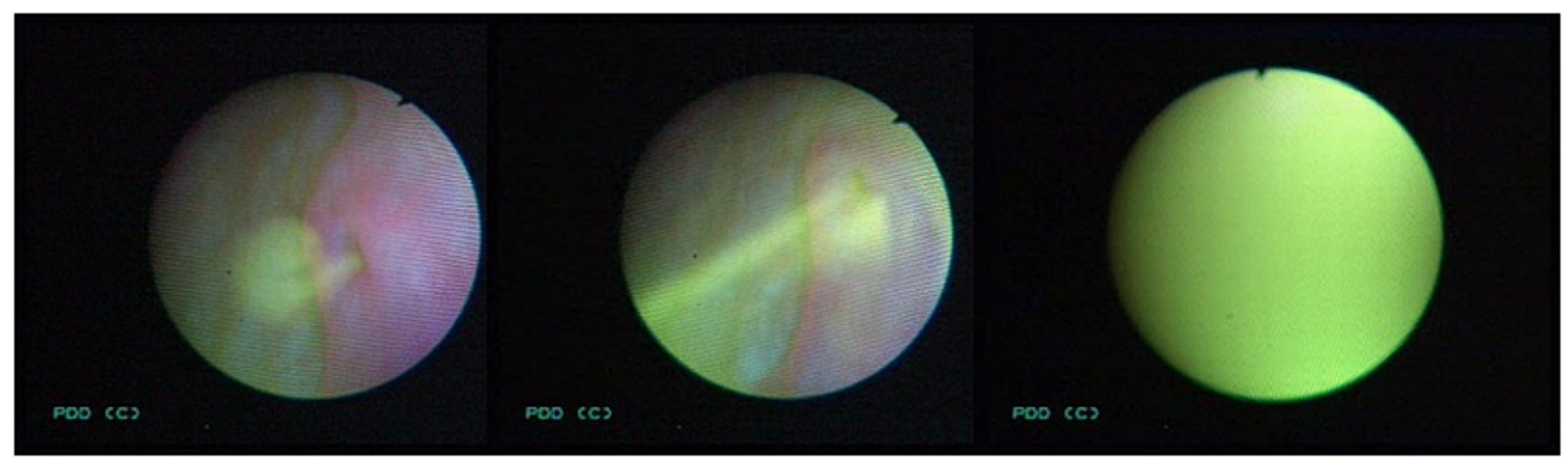

Figure 2. Three images of green fluorescence from urine excited by blue light $(430 \mathrm{~nm})$ observed in a flexible cystoscope in the OPD as the urine enters the bladder from the kidney over an interval of 0,5 and 10 seconds. The fringes present in some of the frames originate from interference between the lattice structure of the coherent fibre bundle of the flexible cystoscope and the pixels of the CCD chip in the camera attached to the cystoscope. This effect is also known as the Moiré-effect (C) Gregers Hermann.

A previous study has shown that histological diagnosis of non-muscle invasive (NMI) bladder cancer in biopsies obtained during flexible cystoscopy in the OPD in local anaesthesia is as good as the golden standard which is biopsies obtained through rigid cystoscopes the OR from patients in general anaesthesia ${ }^{8}$. Choice of treatment in non-muscle invasive bladder cancer can therefore be based on outpatient procedures which is faster and less resource requiring for as well the patient as the health system. 


\section{MATERIALS AND METHODS}

\subsection{Photosensitiser}

To simulate the effect of PpIX being bound to cell membranes of mitochondria, samples of PpIX adsorbed onto granulates of Polyvinylalcohol(PVA, Sigma Aldrich\#36162, 98-99\% Hydrolysed, Mw 146.000-186.000 Sigma-Aldrich Denmark A/S,Vallensbæk, Denmark) were prepared. The purpose of adsorbing PpIX to PVA was to enhance the triplet state of the dye $\mathrm{e}^{9,10}$ thereby simulating the photobleaching conditions of PpIX bound in a tumour. As the PpIX was adsorbed from an aqueous solution of PpIX, water was also present as an oxygen source as would the case in a tumour cell in the bladder. The PpIX was added to the PVA as a $0.01 \mathrm{w} / \mathrm{v} \%$ aqueous solution of Protoporphyrin IX disodium salt supplied by Sigma Aldrich\# 258385, (Sigma-Aldrich Denmark A/S,Vallensbæk, Denmark). Samples containing PVA granulates with adsorbed PpIX were kept in disposable fluorescence cuvettes (PMMA) with a path length of $1 \mathrm{~cm}$ from Kartell(VWR Denmark, Herlev, Denmark).

\subsection{Cystoscope light source}

A tailor-made LED light source was developed to make a proof-of-concept that a light source in the green spectral region of the visible spectrum could replace the filtered Xe-discharge lamps normally used in PDD.

To match the optical power required for the cystoscope, a commercially available high power LED, normally used in projectors, was selected. The LED chip used in the tailor-made light source is a Luminus Devices CBT 120 with a nominal wavelength of $528 \mathrm{~nm}$.

The LED operates at a current of $18 \mathrm{Amp}$ and a forward voltage of $4.3 \mathrm{~V}$. As the optical output of the diode is rated at $4.1 \mathrm{~W}$ at these operating conditions approximately $74 \mathrm{~W}$ is lost as heat during operation. Consequently, the LED requires a substantial amount of air cooling as can be seen in figure 3, where the lay-out of the light source is shown.

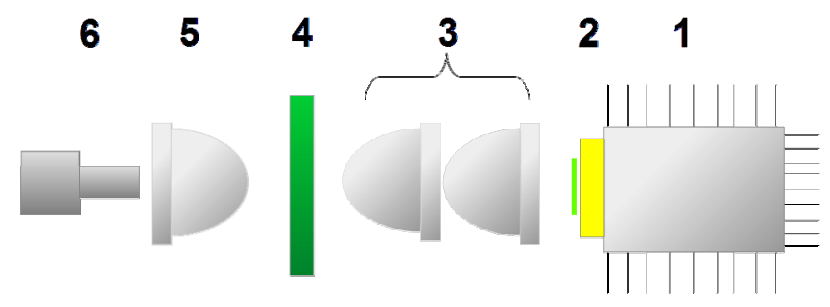

Figure 3. Lay-out of LED light source developed during the course of this project. 1 Heat sink for LED 2. $525 \mathrm{~nm}$ LED 3. Hybrid Aspherical lens pair,4. Bandpass filter 5. Aspherical lens 6. Ferrule of light guide

From an optical point of view, the design closely matches that of a condenser used in projectors. A pair of hybrid aspherical lenses (Each lens F=20 mm, diameter $25 \mathrm{~mm}$, VIS AR coated, Edmund Optics Ltd \#66001, UK) is used to collect the light form the LED chip most effectively. The LED is placed in the focal plane of the lens pair. By using an aspherical lens ( $\mathrm{F}=15 \mathrm{~mm}$, diameter $25 \mathrm{~mm}$, VIS AR coated, Edmunds Optics Ltd \# 67252, UK) to couple light into a 495NA light guide (Storz, Tüttlingen, Germany) an intensity $400 \mathrm{~mW} / \mathrm{cm}^{2}$ can be achieved at the output of the light guide. As can be seen in figure 3, a bandpass filter (Brightline 525-30, Semrock, $525 \mathrm{~nm}$ center wavelength, $30 \mathrm{~nm}$ bandwidth) is inserted in optical path between the condensing aspherical lenses. The bandpass filter serves two purposes as shown in figure 4. One is to cut off any blue light from the LED that could excite green fluorescence form the urine. The other is to prevent residual yellow and red light from the LED to enter the bladder as this would confound the auto fluorescence of the bladder mucosa and the sensitised red fluorescence from the tumours. 


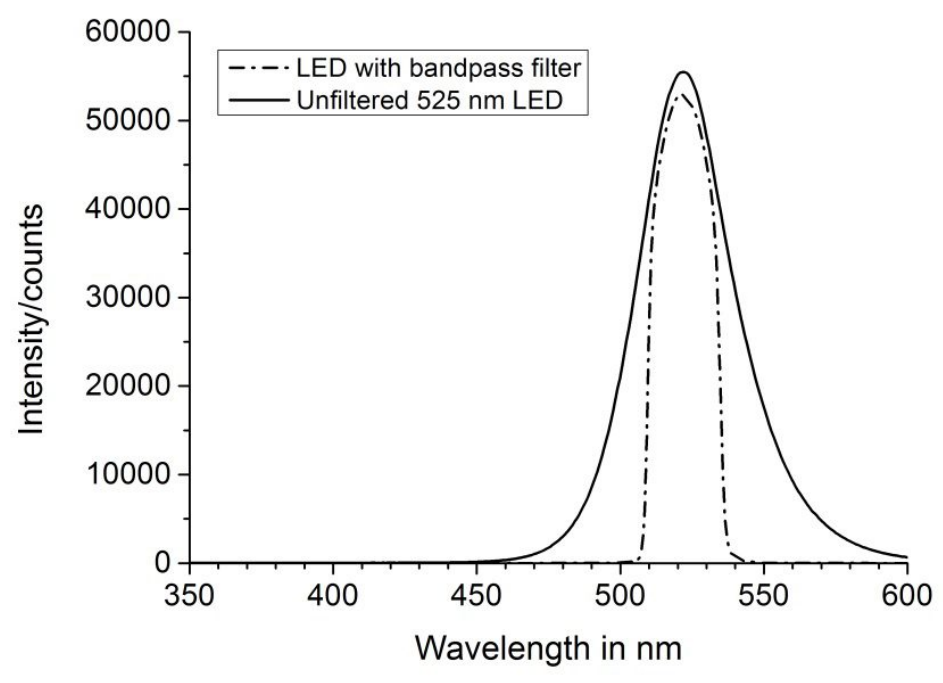

Figure 4. The emission spectrum of $525 \mathrm{~nm}$ LED CBT 120 from Luminus Devices without bandpass filter and with a Semrock Brightline 525-20 filter with a bandwidth (FWHM) of $20 \mathrm{~nm}$.

\subsection{Optics}

In order to prevent excitation light from the LED light source to enter the endoscope camera (Tricam Storz, Tüttlingen, Germany) a rejection filter was placed in the eyepiece. The transmission spectrum of the filter is show in figure 5 was measured using the CARY 100 spectrophotometer.

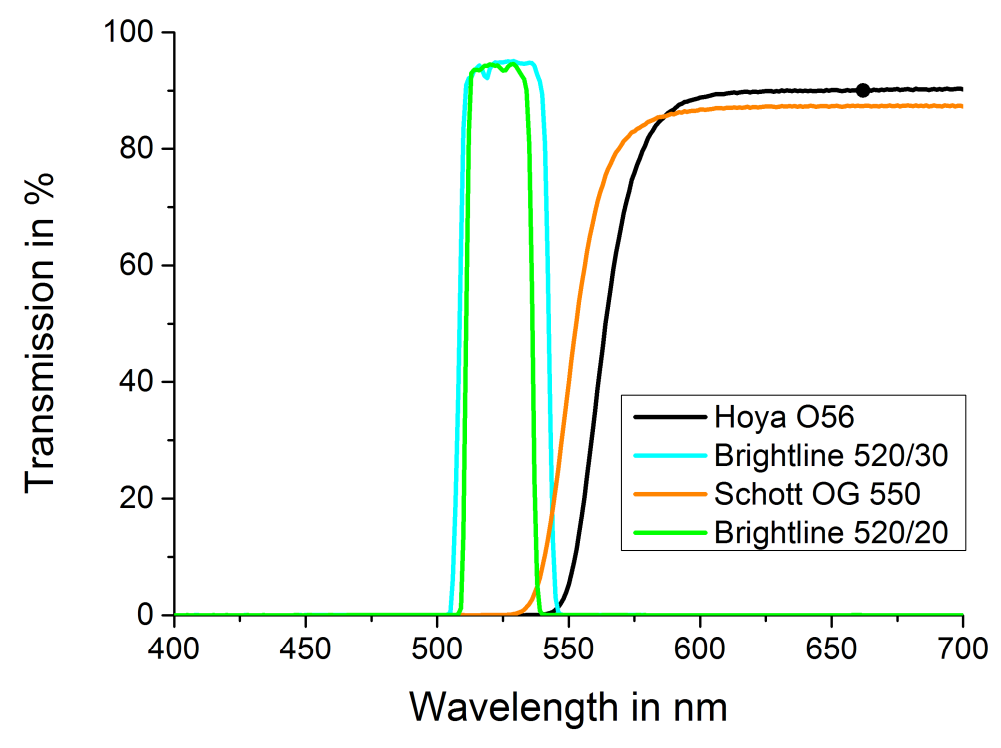

Figure. 5. Transmission spectrum of eyepiece filter measured using a CARY 100 spectrophotometer. This filter allows the surgeon to examine the bladder without having to change between blue and white light (conventional PDD).

It is known from literature ${ }^{11}$, that some overlap between excitation light and the bandpass of the observation filter is desirable to get a good contrast of the fluorescence image. Consequently, three different bandpass filters of the LED 
excitation light source were tested to determine the optimal combination of eye piece (observation) filter of the cystoscope and the LED light source. Consequently, the long wave pass LWP filter OG550 from Schott was selected.

\subsection{Cystoscopes}

A 22 French white light cystoscope (Karl Storz, Tuttlingen, Germany) was used for the procedure in the OR.

\subsection{Spectrometers and power meter}

The absorption spectrum of urine and the optical filters was recorded using a CARY 100 (Agilent Technologies, Santa Clara. CA, USA).

The photobleaching of PpIX were measured using a Fluorolog 3 spectrofluorometer (Horiba Jobin Yvon, Longjumeau, France) in the kinetics mode. PpIX samples prepared as described in section 2.1 were placed in the spectrofluorometer and measured in the backscatter geometry. The photobleaching was excited by $430 \mathrm{~nm}$ and $525 \mathrm{~nm}$ respectively with a bandwidth of $10 \mathrm{~nm}$. The decay was recorded using the kinetics setup of the spectrometer at the emission wavelength $635 \mathrm{~nm}\left(5 \mathrm{~nm}\right.$ bandwidth). The intensity of the excitation light was $7.35 \mathrm{~mW} / \mathrm{cm}^{2}$ for $430 \mathrm{~nm}$ and $3.58 \mathrm{~mW} / \mathrm{cm}^{2}$ for 525 $\mathrm{nm}$. The intensity was measured using a PM100USB power meter fitted with a S120VC photodiode power sensor both from Thorlabs (Thorlabs AB, Gothenburg, Sweden).

The emission spectrum of the proof-of-concept LED-based PDD light sources were measured using an Ocean Optics QE65000 (Dunedin, FL, USA) CCD spectrograph with 300 lines $/ \mathrm{mm}$ ruled grating and 25 micron slit. This corresponds to wavelength range of 200-950 $\mathrm{nm}$ and a spectral resolution of $2 \mathrm{~nm}$. An OD4 reflective ND filter (Thorlabs AB, Gothenburg, Sweden) was mounted at the spectrometer entrance slit to avoid saturation of the QE65000.

\section{RESULTS AND DISCUSSION}

\subsection{Spectral measurements of urine and Protoporphyrin IX}

Urine exhibits strong fluorescence in the blue-green spectral range when excited with blue light of commercially available endoscopic systems for photodynamic diagnosis. In order to assess the wavelength range that will excite the metabolites of urine, the absorption spectrum of urine was recorded using a Cary100 spectrophotometer (Fig 6).

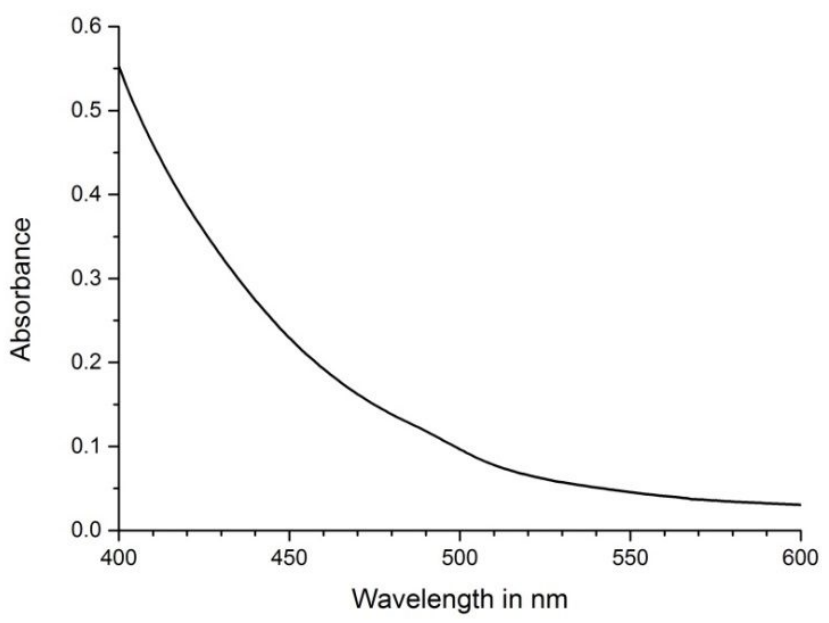

Figure 6. VIS Absorption spectrum of human urine in a10 $\mathrm{mm}$ OS cuvette measured in double beam CARY 100 spectrophotometer with a $10 \mathrm{~mm}$ OS cuvette containing MilliQ water in the reference beam. 
Figure 6 shows that blue light (430nm centre wavelength) of commercial available PDD systems, is strongly absorbed by urine $(50 \%$ at $430 \mathrm{~nm})$ and will cause the urine to fluoresce, but wavelengths above $500 \mathrm{~nm}$ only are absorbed marginally $(10 \%$ at $525 \mathrm{~nm})$ by urine in a $10 \mathrm{~mm}$ cuvette. It is, however, worth mentioning that the optical path length of the bladder is significantly larger than $10 \mathrm{~mm}$ due to fact that the urine is excited in backscattered fluorescence geometry rather than simple transmission geometry, the total optical path length more likely is $20 \mathrm{~mm}$ in the best case and $50 \mathrm{~mm}$ to $100 \mathrm{~mm}$ under clinical observation conditions. Assuming the absorbance to follow the Beer-Lambert law, further increasing the optical path length causes an even greater absorbance of the blue excitation light and hence a much stronger fluorescence signal from urine can be expected at $430 \mathrm{~nm}$ than $525 \mathrm{~nm}$.

The results of the fluorescence measurements shown in figure 7 demonstrate a correlation between light absorption in urine and the magnitude of fluorescence of urine and PpIX respectively.

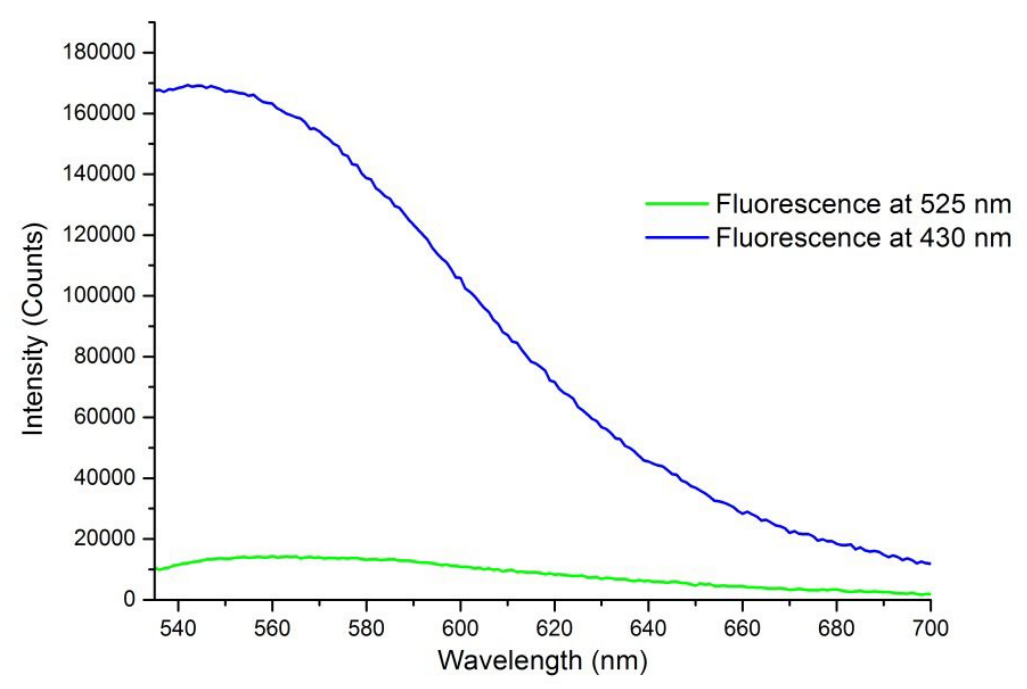

Figure 7. Backscattered fluorescence spectrum of urine measured in a disposable plastic cuvette with optical path length $10 \mathrm{~mm}$ measured at $430 \mathrm{~nm}$ and $525 \mathrm{~nm}$ excitation wavelength respectively.

It is, however, important to note that fluorescence spectra shown in figure 7 only reflect the spectral properties of urine in vitro. During PDD in a bladder, the intensity of green fluorescence of urine will completely confound that of PpIX as the path length of excited volume is more than an order of magnitude larger than that of the tumour containing PpIX.

The fluorescence spectra in figure 7 demonstrate how the fluorescence of urine can be reduced by more than an order of magnitude using a longer wavelength for excitation of PpIX. As can be observed from the fluorescence spectrum of PpIX in water shown in figure 8 , the fluorescence intensity of PpIX is not compromised by changing the excitation wavelength from $430 \mathrm{~nm}$ to $525 \mathrm{~nm}$. 


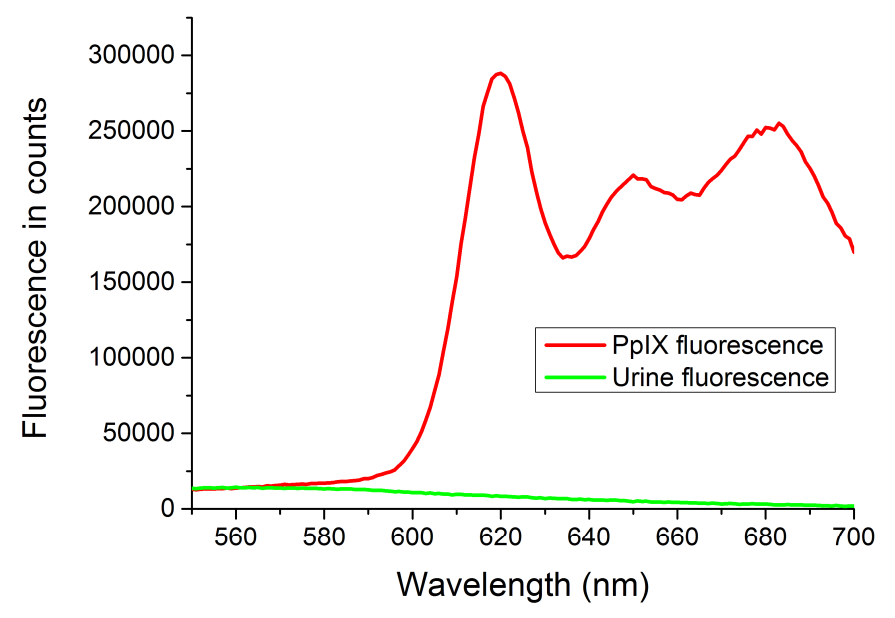

Figure 8. Fluorescence spectrum of PpIX and urine at $525 \mathrm{~nm}$ excitation.

\subsection{Photobleaching}

Apart from the ubiquitous issue of green fluorescence ${ }^{12}$ caused by blue light excitation in PPD another problem observed in PDD of bladder tumours is the bleaching of the PpIX. This effect shortens the available time for examining the bladder using PDD during cystoscopy. In this section it is shown how this effect can be minimised by the use of green excitation light for PDD.

Photobleaching of organic dyes like PpIX is a commonly observed phenomenon in fluorescence microscopy as well as in photodynamic diagnosis of tumours. There are many contributing factors to this effect but the main initial photochemical step in this process is the creation of a triplet state of the excited dye molecule and the presence of molecular oxygen in the tissue. PpIX exhibits both singlet-singlet transitions (origin of the $635 \mathrm{~nm}$ fluorescence used in PDD) as well as an excited triplet state transferring energy to molecular oxygen forming singlet oxygen (used in photodynamic therapy (PDT)). It is the formation of the latter species that triggers a sequence of chemical reactions ${ }^{13,14}$ causing bleaching of PpIX in the cuvette experiment described in this paper.

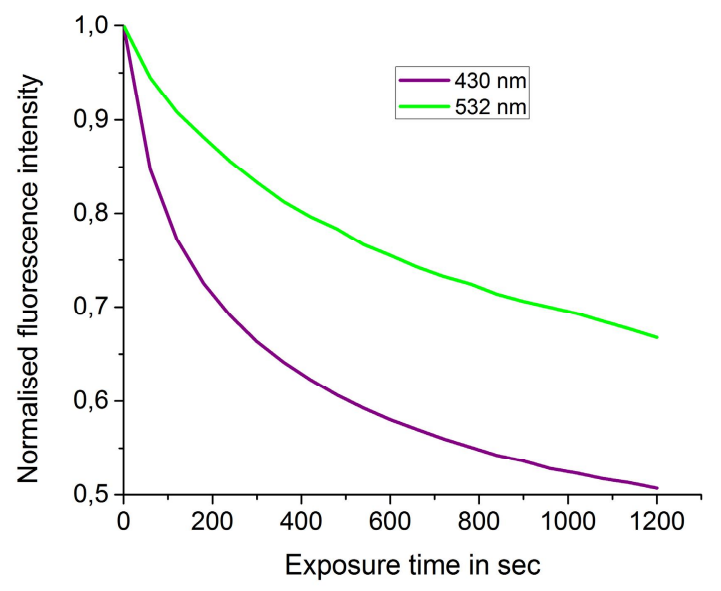

Figure. 9. Photobleaching of PpIX adsorbed on PVA granulates at two different excitation wavelengths. Power density for bleaching was $7.35 \mathrm{~mW} / \mathrm{cm}^{2}$ for $430 \mathrm{~nm}$ and $3.58 \mathrm{~mW} / \mathrm{cm}^{2}$ for $532 \mathrm{~nm}$, respectively. The bleaching was measured as a decrease in the fluorescence peak at $635 \mathrm{~nm}$. 
To test the hypothesis that green light $(525 \mathrm{~nm})$ would cause less photobleaching than blue light $(430 \mathrm{~nm})$ used for PDD, two samples of PpIX adsorbed onto granulates of PVA were prepared as described in section 2.1. PVA granulates were placed in a cuvette and placed in the spectrofluorometer and excited by $430 \mathrm{~nm}$ and $525 \mathrm{~nm}$, respectively with a bandwidth of $10 \mathrm{~nm}$. The decay was recorded using the kinetics setup of the spectrofluorometer at the emission wavelength $635 \mathrm{~nm}$ (5nm bandwidth). As can be seen in figure 9, the use of blue light (430 nm) significantly bleaches the PpIX at a much higher rate than $525 \mathrm{~nm}$ light.

This statement is substantiated by making a double exponential fit of the two decay curves in figure 10 . This was done using Origin ${ }^{\circledR} 8.1$ (OrginLab Corporation, Northampton, MA, USA). As the results show in table 1 and 2, both photobleaching curves in figure 9 can be approximated by a double exponential fit perfectly as can be seen from RSquare value of 0.99 . This is indicative of a "fast", most pertinent to an urologist, and a "slow" component in the photobleaching of PpIX. Publications ${ }^{15,16}$ by others groups confirm this observation. Focusing on the fast component, of photobleaching at 430 and $525 \mathrm{~nm}$ respectively, it can be inferred from the fitting parameters in Table 1 and 2, that the time constants $t_{1}$ of the process at $430 \mathrm{~nm}$ is $66 \mathrm{~s}$ corresponding to bleaching rate $\mathrm{k}_{1}$ of $0.0152 \mathrm{~s}^{-1}$ and that the similar time constant $t_{1}$ at $525 \mathrm{~nm}$ is $775 \mathrm{~s}$ corresponding to a bleaching rate $\mathrm{k}_{1}$ of $0.00129 \mathrm{~s}^{-1}$. This is more than an order of magnitude in difference indicating that the use of $525 \mathrm{~nm}$ light significantly reduces the rate of photobleaching compared to $430 \mathrm{~nm}$.

Table 1. Fitting parameters of photobleaching curve of PpIX at $430 \mathrm{~nm}$.

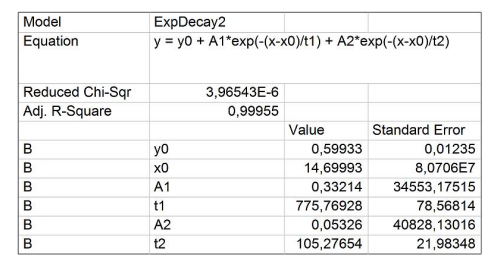

Table 2. Fitting parameters of photobleaching curve of PpIX at $525 \mathrm{~nm}$

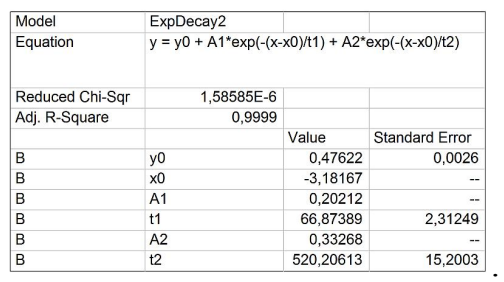

\subsection{In vivo test of $525 \mathrm{~nm}$ excitation light for PDD of bladder tumours}

Based on the observations that the blue light from commercial PDD light sources cause significant green fluorescence in the bladder during PDD as well as photobleaching of the PpIX, a proof-of-concept cystoscope based on the green LED light source described in section 2.2 was implemented.

For a proof-of-concept, 3 patients were selected for testing the efficacy of replacing the conventional light source in the OR by the new LED based light source emitting light at $525 \mathrm{~nm}$ as shown in figure 10. The patients were treated in accord to the Helsinki Declaration; the regulations of the local ethical committee; the Danish guide lines for treatment of bladder cancer and had given informed consent before surgery. The patients had previously had a bladder tumour identified during endoscopy performed in the outpatient department. A Karl Storz PDD D-light system and Karl Storz endoscope for white light (not for blue light) was used. In the beginning of the surgical procedure the endoscope was introduced to the bladder in white light and the bladder examined in white light. Then the white light source was replaced with our tailor-made $525 \mathrm{~nm}$ LED light source shown in fig.10, a longpass filter (Schott OG 550) was placed in the eyepiece of the cystoscope optics and the camera and the bladder was examined. Fluorescence from the tumour was recorded at the same time as urine was observed in the bladder but without green colouring (fig 11 a). Furthermore, it 
was also observed that clear picture could be obtained of the bladder mucosa and blood vessels using only autofluorescence as shown in figure $11 \mathrm{~b}$.

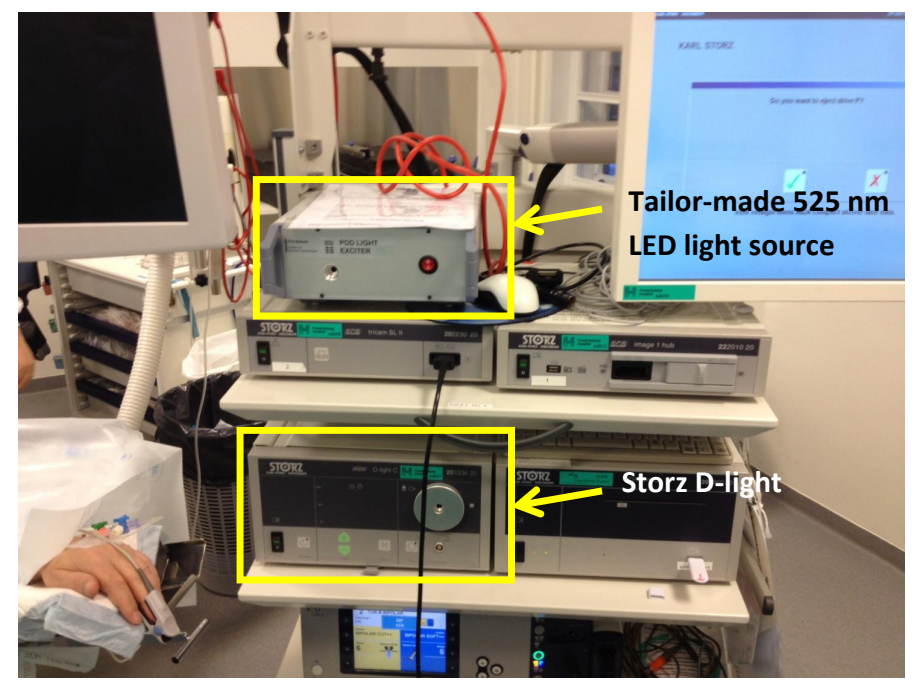

Figure 10. Setup used in the operating room for testing the green $525 \mathrm{~nm}$ LED light source for cystoscopy.

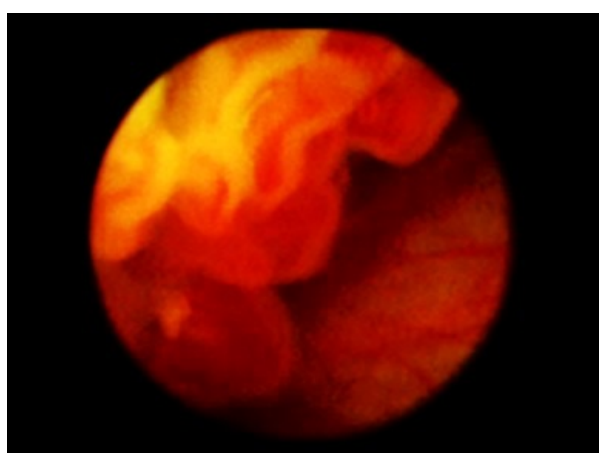

(a)

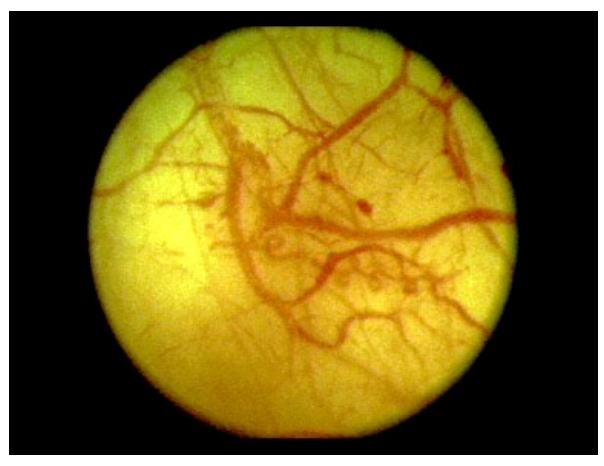

(b)

Fig. 11(a) and 11 (b) shows that the LED light source presented in this article is capable of exciting both sensitised fluorescence of tumours in a bladder as well as autofluorescence of the bladder mucosa without changing the wavelength of the cystoscope light source as would be the case in conventional systems for PDD of tumours in the bladder. Field of view in (a) is $20 \mathrm{~mm}$, whereas field of view in (b) is $5 \mathrm{~mm}$ (c) Gregers Hermann.

\section{FUTURE WORK}

Based on the observations reported in this paper a series of experiments will be needed to prove the efficacy of the new method in order to establish a proper protocol for this method in the clinic including a study of a larger cohort of patients. This will provide us with better statistical grounds for substantiating the advantages of the new method compared to conventional PDD. Furthermore, optical improvements of the proof-of-concept illumination system will be required to boost the autofluorescence image from the cystoscope and for use in flexible endoscopes in the outpatient department. 


\section{CONCLUSIONS}

We have shown that the ubiquitous problem of green fluorescence during PDD for bladder tumours, particularly in flexible cystoscopes, can be circumvented by selecting excitation light in the green spectral range rather than blue spectral range currently used by the commercial systems. It has also been demonstrated that shifting the excitation wavelength from $430 \mathrm{~nm}$ to $525 \mathrm{~nm}$ significantly reduces the photobleaching of the photosensitiser. It is noteworthy that the light source presented in this article is used with the standard white-light cystoscopes and light guides without any blue-light optics.

Furthermore, it was also observed that using green excitation light also made it possible to use the autofluorescence of the mucous membrane in the bladder for general observation provided that a suitable bandpass filter was placed in eyepiece of the endoscope. This may possibly replace the use of white light sources for general viewing during cystoscope based PDD procedures for removal of bladder tumours.

\section{ACKNOWLEDGEMENTS}

The authors wish to thank the Proof-of-Concept initiative of the Danish Government and the Foundation Juchum and the Boemske Foundation for their financial support to this project. Furthermore the authors wish to thank the Novo Nordisk Foundation for support from an exploratory pre-seed grant and Copenhagen Spin-Out for financial support.

\section{REFERENCES}

[1] GLOBALCAN 2008 (Accessed 04 May 2012), http://globalcan.iarc.fr/

[2] Botteman, M.F. et.al., "The health economics of bladder cancer: a comprehensive review of the published literature." Pharmacoeconomics," 21(18), 1315-1330 (2003).

[3] Hamblin, M.R. and Mróz, P.,[Advances in photodynamic Therapy], Artech House Boston \& London, 59-81 (2008).

[4] Hermann, G.G., Mogensen, K., Carlsson, S., Marcussen, N.and Duun, D. , "Fluorescence guided TUR-B reduces bladder tumour recurrence due to less residual tumour tissue after TURB in Ta/T1 patients. A randomised 2-center study," BJU Int. Oct;108(8 Pt 2):E297-303 (2011).

[5] Burger, M., Zaak, D., Stief, C.G., Filbeck, T.Wieland, W.F., Roessler, W. and Denzinger, S., "Photodynamic Diagnostics and Noninvasive Bladder Cancer: Is It Cost-Effective in Long-Term Application?A Germany-Based Cost Analysis", European Association of Urology (EAU), Eur Urol., 52, 142-147 (2007).

[6] M. Babjuk, W. Oosterlinck, R. Sylvester, E. Kaasinen, A. Böhle, J. Palou-Redorta and M. Rouprêt, "EAU guidelines on non-muscle-invasive urothelial carcinoma of the bladder, the 2011 update".European Association of Urology (EAU), Eur Urol. 59(6), 997-1008 (2011).

[7] Leiner, M.J.P., Hubmann, M.R. and Wolfbeiss, O.S., "The total fluorescence of human urine,"Analytica Chimca Acta 198, 13-23 (1987).

[8] Hermann, G.G., Mogensen, K., Toft B.G., Glenthøj, A. and Pedersen, H.M., "Outpatient diagnostic of bladder tumours in flexible cystoscopes: evaluation of fluorescence-guided flexible cystoscopy and bladder biopsies," Scand. J. Urol. Nephrol. 46(1), 31-36 (2012).

[9] Lewis, G.N., Lipkin, D. and Magel, T.T., "Reversible photochemical processes in rigid media - A study of the phosphorescent state, "J.Chem.Soc.Am. 63, 3005-3018 (1941).

[10]Diaz-Garcia, M.E., Pereio-García, R. and Velasco-García, N., "Optical oxygen sensing materials based on the roomtemperature phosphorescence intensity quenching of immobilized Erythrosin B,"Analyst 120, 457-461 (1995).

[11]Gahlen, J., Prosst, R.L. and Herfarth, C.,"Blue light illumination for minimally-invasive fluorescence detection: technology, clinical experience and future perspectives", Min Invas Ther \& Allied Technol, 9(2), 119-124 (2000).

[12]Lovisa, B., Novello, A.M., Jichlinski, P., van den Bergh, H. and Wagniéres, G., "Fluorescence of the bladder washout fluid following cystoscopy: a preliminary study," Proc. SPIE. 7548, 75481 J-1 (2010).

[13]Bonnett, R. and Martínez, G., "Photobleaching of sensitisers used in photodynamic therapy," Tetrahedron 57, 9513 9547 (2001). 
[14]Plaetzer, K., Krammer, B., Berlanda, J., Berr, F. and Kiesslich, T., "Photophysics and photochemistry of photodynamic therapy: fundamental aspects," Lasers Med. Sci, 24, 259-268 (2009).

[15]Robinson, D.J., de Bruijn, H.S., van der Veen, N., Stringer, M.R., and. Star, W. M, "Fluorescence photobleaching of ALA-induced Protoporphyrin IX during photodynamic therapy of normal hairless mouse skin: The effect of light dose and irradiance and the resulting biological effects," Photochemistry and Photobiology, 67(1), 140-149 (1998).

[16]Moan, J., Streckyte, G., Bagdonas, S., Bech, Ø. and Berg, K.,"Photobleaching of Protoporphyrin IX in cells incubated with 5-aminolevulinic acid," Int. J. Cancer 70, 90-97 (1997). 